(g) Audible Monitoring.-There shall be an optional audible monitoring signal synchronized with the pulses.

(h) Safety Precautions.-One of the patient terminals shall be connected to earth and the case. Dangerous potentials shall be excluded from the patient's circuit in the event of valve or component failure.

\section{Constructional Requirements}

Minimum constructional requirements shall be those set out in Inter-Service Specification R.C.S. 1,000. The subcommittee reports that one prototype fulfilling the above specification has worked satisfactorily for over five years.

The Subcommittee is greatly indebted to the following co-opted members who gave valuable assistance in the work: Messrs. Bannister, Bowes, Galloway, Spencer. W. Noble, and Sutton (Technical Research Establishment, Great Malvern); Mr. R. Brennand (R.A.F.); and Mr. P. Stiles (St. Thomas's Hospital).

\section{REFERENCES}

Bauwens, P. (1941). Proc. roy. Soc. Med., 34, 459.

Cluzet, J. (1903). C.R. Acad. Sct. (Paris), 137, 670 . Erb, W. (1883). Handbo

Wood, New York.

Parry, C. B. Wynn (1953). Brain, 76, 229.

Report (1948). Technical, Repair and Development Section, Royal Ai Force, Chessington, 248 M.U. Report No. 13.

Force, Chessington, 1958 a). Medical Research Council, $50 / 727$.

(1950b). Technical, Repair and Development Section, Report No. 30 - (1952). Technical, Repair and Development Section, Report No. 42 - (1953a). Technical, Repair and Development

Ritchie, A. E. (1954). Rep. med. Res. Coun. (Lond.), No. 282, pp. 239-262.

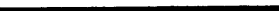

\section{CULLEN'S SIGN}

BY

E. F. B. CADMAN, M.D., M.R.C.P., D.C.H. Consultant Physician, Southport Hospitals Group

In 1918 T. S. Cullen reported a case in which a blue discoloration of the umbilicus was noted. By analogy with a case described earlier by Ransohoff (1906), in which a localized yellow umbilical stain occurred, free bile being found in the peritoneal cavity at operation, Cullen correctly postulated the presence of a haemoperitoneum and, from other evidence, deduced the cause of this to be a ruptured tubal pregnancy. A number of similar cases have since been reported (Novak, 1922; Strube, 1923 ; Tanner, 1932 ; Smith and Wright, 1935). The operative findings of Stabler (1934) and Way (1941) showed that the skin discoloration was due to blood in the subcutaneous tissue, as in an ecchymosis. In the same way, therefore, as in this latter condition, the exact colour of the sign may vary (Jackson, 1922 ; Neumann, 1928 ; Fallon and Manning, 1949). The abnormal staining of the subcutaneous tissue need not be confined to the umbilicus (Neumann, 1928 ; Stabler, 1934 ; Fallon and Manning, 1949), and may even involve previous abdominal operation scars (Gold, 1926 ; Schmitz, 1932 ; Smith and Wright, 1935). In all, it has been possible to trace about 30 reported cases of Cullen's sign associated with ruptured tubal pregnancy, though Fallon and Manning (1949) claim to have found 70 such instances.

Two years after Cullen's original description, Turner (1920) described two cases of acute pancreatitis. The first exhibited a somewhat extensive Cullen's umbilical sign accompanied by free intraperitoneal fluid, and eight similar cases have since been recorded (Johnston, 1930 ; Petrivalsky, 1931 (3 cases) ; Stutzer, 1931 ; Fallis, 1937 (3 cases) ). Turner's second case showed a dirty green loin discoloration due to direct tracking of pancreatic fluid to the subcutaneous tissue. It is to this latter sign that the eponym " Grey Turner's sign " has been applied (Wakeley, 1952; Bailey, 1954). Only two other examples of this sign have been traced in the literature (Cox, 1945 ; Kelley, 1957) and only the former was associated with pancreatitis. Although both signs are rare, Cullen's sign would appear to be more common in acute pancreatitis than Grey Turner's sign.

In view of the above discussion it is not surprising that Cullen's sign is commonly regarded as being due to a haemoperitoneum associated with a ruptured tubal pregnancy or, less commonly, acute pancreatitis (Bailey, 1954). The problem is not quite so simple, however, as the presence of Cullen's sign with either a ruptured tubal pregnancy or acute pancreatitis does not invariably imply the presence of a haemoperitoneum (Pfeiffer, 1923 ; Smith and Wright, 1935 ; Fallis, 1937). Further, the sign has been reported with numerous other conditions, with and without an accompanying haemoperitoneum.

Of these alternative causes, the most frequent is rupture of the rectus abdominis muscle, when the skin discoloration may occur at the umbilicus (Perman, 1922 ; Von Renner, 1924 ; Halperin, 1928 ; Way, 1941) or elsewhere (Stoeckel, 1901 ; Cullen and Brödel, 1937 (Case 2); Teske, 1946). No blood was present in the peritoneal cavities of any such cases except for that described by Toft (1915).

The occurrence of Cullen's sign with ante-partum rupture of a caesarean section scar was first reported by Gerrard (1938), no free blood being present in the peritoneal cavity. Similar cases have since been recorded (Galloway, 1939; Gough, 1939; Way, 1941). Finally, Cullen's sign has been noted in association with the following conditions: acute salpingitis (Schumann, 1923 ; Hadley, 1940) ; haemorrhagic ascites (Sternberg, 1922 ; Kapsinow, 1925) ; haemorrhage in association with acute yellow atrophy of the liver (Schumann, 1936); ovarian cyst (Busch, 1922); and traumatic haematoma of the cave of Retzius (Goinard and Curtillet, 1934).

The exact significance of Cullen's sign is thus open to doubt. Interest in the mode of production and significance of the sign was stimulated by the observation of Case 1 described below. Two earlier examples were then reviewed (Cases 2 and 3 ). It is considered that a study of these three cases throws light on some of the unanswered problems. The present paper is only the fourth occasion on which as many as three cases of Cullen's sign have been reported together (Petrivalsky, 1931 ; Fallis, 1937 ; Way, 1941). In none of these 12 patients was the cause a ruptured tubal pregnancy.

\section{Case 1}

One week before being seen on August 18, 1956, a 67year-old man suddenly developed severe lumbar backache radiating into the left leg. He was tender over his left sacro-iliac joint and there was limitation of the straight-leg raising test on the same side.

He improved with bed rest, but had a severe recurrence on October 21 and morphine was required. The next day he had a florid complexion with a B.P. of $120 / 80 \mathrm{~mm}$. $\mathrm{Hg}$ and a haemoglobin of $8.7 \mathrm{~g} . / 100 \mathrm{ml}$. He was tender in the left loin posteriorly, and anteriorly a large tender nonpulsatile mass was palpable. An $x$-ray film showed a large calcified abdominal aortic aneurysm extending to the left of the spine. Two days later the abdominal mass was more tender, there was blueing at the umbilicus, and the central part of the mass was pulsatile. Twenty-four hours later 
shock developed, the blood pressure falling to $90 / 60 \mathrm{~mm}$. $\mathrm{Hg}$, the pulse rate rising to 104 , and the haemoglobin falling to $4.8 \mathrm{~g} . / 100 \mathrm{ml}$. Blood transfusions and morphine were given, but he died the following day.

Post-mortem examination revealed an obese pale man with umbilical blueing which on incision was seen to be due to blood in the subcutaneous tissues. The heart showed evidence of an old coronary thrombosis, and there was some pulmonary congestion. On opening the abdominal cavity dark blood was seen extraperitoneally on the left side deep to the abdominal muscles. Anteriorly this could be followed to the extraperitoneal tissue deep to the umbilical scar, superficial to which was the blood-stained area of subcutaneous tissue. There was a small break in the continuity of the blood about $1 \mathrm{~cm}$. wide. This was situated about $3 \mathrm{~cm}$. from the umbilicus, but on massaging this area the two patches of blood easily joined. Posteriorly the extraperitoneal blood was continuous with a large retroperitoneal haematoma migrating from a ruptured saccular aneurysm, $10 \mathrm{~cm}$. in diameter. This arose from the abdominal aorta below the left renal artery. There was no blood in the peritoneal cavity.

\section{Case 2}

A 39-year-old woman was first seen in March, 1949, being under the care of Lord Cohen of Birkenhead. Three months previously she had developed an influenzal-like illness followed one month later by diarrhoea which had persisted. A month before she was seen, swelling of the legs and face developed. Clinically her general condition was quite good, but some oedema of the lower trunk, legs, and face was present. There was a suggestion of ascites, but nothing else abnormal was detected in the heart, lungs, or abdomen. Urinalysis revealed a trace of albumin. A little later a blue discoloration was noted at the umbilicus and a vague mass was felt under the right costal margin. Vaginal examination suggested the presence of a high pelvic mass. Abdominal paracentesis was carried out, 7 pints (4 litres) of heavily blood-stained fluid being obtained. Following this the liver was felt to be enlarged. Later the patient developed jaundice, finally dying 15 days after Cullen's sign had been noted.

Post-mortem examination showed a body with marked icterus and Cullen's sign still visible. The abdomen was distended and $3 \frac{1}{2}$ pints ( 2 litres) of blood-stained peritoneal fluid was present. Nodules of tumour were revealed in the liver and over the pelvic organs. A large carcinomatous ulcer was present in the hepatic flexure of the colon with wide extensions to the surrounding tissues. Extensive retroperitoneal haemorrhage arose from these. There was widespread lymph node involvement of the para-aortic chain. A little fluid was present in the left pleural space and a terminal bronchopneumonia was also found. Histologically the growth was a spheroidal cell carcinoma.

\section{Case 3}

On April 8, 1954, a 71-year-old woman was admitted to the Liverpool Royal Infirmary under the care of the late Mr. M. Silverstone. She had always been constipated, but more recently had developed periumbilical pain radiating round from the back and she had noted that her abdomen was swollen. The patient was pale (haemoglobin $7.5 \mathrm{~g} . /$ $100 \mathrm{ml}$.). The abdomen appeare distended and there was doubtful shifting dullness. A barium-enema $x$-ray examination was nermal apart from evidence of a large soft-tissue pelvic swelling lifting up the colon. A few days later a blue discoloration was noted around the umbilicus. Vaginal examination confirmed the presence of a mass to the left of the uterus. After blood transfusions, operation was performed on April 20. A haemoperitoneum was found with old adherent clot on the small bowel and sigmoid colon. Blood was oozing from a large vascular tumour adherent to the back of the uterus, which was itself enlarged. Total hysterectomy was performed, including most of the mass but leaving behind the tubes and ovaries. Some of the mass had to be left in the outer end of the broad ligament into which it extended. The patient made a good recovery.

Examination of the specimen showed a uterus enlarged ( 10 by 5 by $7 \mathrm{~cm}$.) by several intramural fibromyomas and containing in the cavity two large endometrial polyps and one small endocervical polyp. Adherent to the left and posterior surfaces of the uterus was a collapsed cystic tumour, $10 \mathrm{~cm}$. in diameter. It was continuous with a soft intramural fibromyoma. The wall of the cavity was thick and ragged, suggesting a degenerated fibromyoma. Histologically it was an undifferentiated tumour, probably of mesenchymal origin (Mr. S. Bender).

\section{Discussion}

Two earlier theories have been propounded to explain the development of Cullen's sign, but each of these immediately runs into difficulties, as the presence of a haemoperitoneum is essential to both. As is emphasized by Case 1 (and others already enumerated) this is not an invariable accompaniment of the sign. Conversely, the sign is very uncommon in the presence of the relatively frequent states of haemoperitoneum (Case 3) or haemorrhagic ascites (Case 2 ; Sternberg, 1922 ; Kapsinow, 1925).

In the first theory the presence of an anatomical defect of the umbilical parietal peritoneum was suggested. There are undoubtedly small blind pits in this region (Cullen, 1916) but the peritoneum is intact in them. This is true even in the case of an umbilical hernia, and, in any event, on embryological grounds no such defect is to be expected.

The alternative theory assumes a physiological breach in the umbilical peritoneum whereby blood pigment is taken up by the local lymphatic vessels and deposited in the nearby subcutaneous tissue. That such lymphatic vessels exist is well known (Cullen, 1916), but there is no evidence that selective absorption takes place at the umbilicus (Higgins and Graham, 1929) ; and, secondly, it is the role of lymphatic vessels to remove such pigment to the regional lymph nodes and not to deposit it en route in the subcutaneous tissue.

The occurrence of secondary carcinomatous deposits at the umbilicus lends little support to the above theories, as in the first place such tissue is invasive and need not necessarily follow anatomical pathways. Secondly, it is rarely certain whether the spread has been transperitoneally or extraperitoneally, from the upper abdomen via the liver and its round ligament, or from the pelvis via the obliterated hypogastric arteries or urachus. Likewise the exact reason for the development of umbilical endometriosis is unknown.

\section{Theory of Extraperitoneal Spread of Blood}

The findings in Case 1 were unique. In this example blood could be traced extraperitoneally (with only two small interruptions) from a retroperitoneal source (ruptured aortic aneurysm) to a Cullen's sign. An abdominal wall ecchymosis with a ruptured abdominal aortic aneurysm is extremely rare (Beebe, Powers, and Ginouves, 1958). Case 1, therefore, gave powerful support to a third theory that the basic underlying cause of Cullen's sign was the extraperitoneal spread of blood and that the occurrence of a haemoperitoneum was purely fortuitous. This hypothesis was originally proposed by Fallis (1937), who described two cases of acute pancreatitis which showed the sign. Although neither had any free intraperitoneal fluid, both did exhibit extensive retroperitoneal and extraperitoneal haemorrhage. In the same way, Cases 2 and 3 described above did show possible essential prerequisites for the production of the sign, though both also exhibited intraperitoneal fluid. In Case 2 there was extensive retroperitoneal and mesocolon haemorrhage, whilst in Case 3 the vascular tumour burrowed out into the broad ligament towards the lateral pelvic wall. In neither case was there a simple clear-cut rupture of a blood vessel into the peritoneal cavity.

There is much additional evidence to support this theory. The anatomy of the extraperitoneal space has recently been 
studied with fresh interest in view of the development of presacral pneumography (Rivas, 1950). These investigations have shown that there is free communication between the extraperitoneal tissue of the abdominal wall, the retroperitoneal space, the visceral mesenteries, and the broad ligament. Blood getting into any one such compartment may therefore be expected to be able to move into an adjacent compartment. Thus blood in the retroperitoneal space might well seep through to the extraperitoneal layer of the abdominal wall, provided that the driving force (the systemic blood pressure) is not released by rupture into the peritoneal cavity. Blood in this layer will be directed to the umbilicus by the folds formed by the obliterated hypogastric arteries and the round ligament of the liver. Adherent to the deep surface of the umbilicus is a thickening of the transversalis fascia, but in $16 \%$ of individuals this is absent or displaced (Poirier and Charpy, 1912), so that in these cases there is direct access from the extraperitoneal space to the subcutaneous tissue (Begg, 1927). An alternative route to the surface is into the rectus muscle sheath below the linea semicircularis and then through the anterior wall of the sheath along the perforating branches of the inferior epigastric artery (Cullen and Brödel, 1937).

Many cases in the literature provide illustrations of blood, or other fluids, following the pathways mentioned above, to a lesser or greater extent. Such cases not showing Cullen's sign might well have exhibited it if the spread of blood had been even more extensive. Thus two cases of retroperitoneal haemorrhage have shown spread of blood to the extraperitoneal tissue of the abdominal wall (Cullen, 1916; Sachs and Macht, 1953), similar to Case 1. It is probably significant that the only three cases of bloodstained ascites showing Cullen's sign were all associated with large extraperitoneal neoplasms (Case 2 ; Sternberg, 1922 ; Kapsinow, 1925). In other instances the spread has been from the broad ligament to the pelvic and abdominal walls (Paucot, 1924 ; Wilens, 1936 ; Roberts, 1949) or the reverse (Von Renner, 1924). In Ransohoff's (1906) case of rupture of the common bile duct intense yellowish discoloration of the extraperitoneal layer of the anterior abdominal wall was found at operation, so this may well have been the true cause of the umbilical stain rather than the bile in the peritoneal cavity.

More anteriorly blood may arise in the rectus muscle sheath and spread superficially by the pathways described above whether or not actual skin staining occurs (Von Renner, 1924 ; Culbertson, 1925 ; Cullen and Brödel, 1937 ; Way, 1941 ; Teske, 1946). Should the blood extend deeply, it may reach the extraperitoneal layer of the abdominal wall (Cullen and Brödel, 1937 (Case 1); Torpin, 1943 ; Adam, 1947 ; Joffe and Van Ryzin, 1952), the broad ligament (Von Renner, 1924), or the cave of Retzius (Perman, 1922; Zohman, 1933). The reverse of the latter pathway explains the presence of Cullen's sign seen in a case of traumatic haematoma in the retropubic space (Goinard and Curtillet, 1934).

The umbilical discoloration described by Turner (1920) in acute pancreatitis is probably produced by the same mechanism (Fallis, 1937). Whether the sign is localized (Fallis, 1937) or diffuse (Turner, 1920 ; Cox, 1945) probably depends on the enzymal concentration in the extravasated fluid.

The pathological anatomy of certain other diseased states gives additional support to the existence of the pathways mentioned above. Thus extravasation of urine from extraperitoneal rupture of the bladder may spread to the subcutaneous tissue at the umbilicus (Bailey, 1954). This same mechanism is the probable explanation of an acquired urinary fistula discharging at the umbilicus in which no evidence of a persistent urachus can be found (Begg, 1927). Very rarely, sepsis of the broad ligament may come to the surface at the umbilicus (Cullen, 1916), or, conversely, superficial sepsis may penetrate deeply to the extraperitoneal tissue (Greig and Shucksmith, 1950).

\section{Criticisms of the Theory}

Certain criticisms of the theory of the extraperitoneal spread of blood come to mind, however. Retroperitoneal haemorrhage is relatively common, and yet Cullen's sign is very rare. The following are some of the factors which make the development of the sign less likely to occur when haemorrhage takes place in any part of the extraperitoneal pathway: a posterior-that is, retroperitoneal-rather than an anterior source of bleeding; a capacious extraperitoneal space (Joffe and Van Ryzin, 1952); the early rupture of the parietal peritoneum to give a haemoperitoneum; the development of shock; and early surgical treatment aimed at stopping the haemorrhage or, incidentally, releasing the blood from the extraperitoneal space. In many potential cases of Cullen's sign the time factor is probably all important as to whether the sign appears or not. Even with haemorrhage as superficial as that within the rectus muscle sheath anything from four to ten days must elapse before skin discoloration appears (Teske, 1946). In the case of a ruptured tubal pregnancy, the rarity (a little over $1 \%$ ) of purely intraligamentary rupture is an additional factor operating against the development of the sign (Wilens, 1936).

Of all the cases of Cullen's sign noted in the literature, in only three is information available about the abdominal wall extraperitoneal tissue. The findings in Gerrard's (1938) case are in keeping with the present theory. In the other two cases the evidence is less helpful. Stabler's (1934) case exhibited a laterally placed Cullen's sign, and he therefore postulated intraligamentary rupture of a tubal pregnancy leading to extraperitoneal spread of blood. Operation, however, revealed a haemoperitoneum with no evidence of subperitoneal haemorrhage. The case reported by Fallon and Manning (1949) was very similar, and they claimed that at operation " no anomalies were noted inside the abdominal wall." In both these cases, however, it is possible that extraperitoneal blood was not seen at operation because it had by then seeped away, as in Case 1 described above.

\section{Summary and Conclusions}

The various causes of Cullen's sign are described. The commonest in order of frequency are ruptured tubal pregnancy, rectus muscle haemorrhage, acute haemorrhagic pancreatitis, and rupture of the uterus. It is stressed that haemoperitoneum is not an invariable accompaniment of Cullen's sign or of the various underlying pathological states associated with it.

Three further examples of the sign are reported, the associated conditions being a ruptured abdominal aortic aneurysm, carcinoma of the colon, and a uterine tumour.

The various theories regarding the mechanism of the production of the sign are discussed. It is concluded that Cullen's sign is primarily an indication of the presence of blood or blood-stained fluid in the abdominal wall. The blood may arise retroperitoneally (most often from the Fallopian tubes, pancreas, or uterus) and spread in the extraperitoneal tissues to the subcutaneous tissue at the umbilicus. Alternatively, the blood may arise within the abdominal wall itself, usually from the rectus muscle. The occurrence of intraperitoneal haemorrhage with the sign is extremely frequent but purely coincidental.

The sign is very commonly, but not necessarily, an indication for surgical intervention. Future cases coming to operation or necropsy should be studied with this theory in mind.

I am grateful to Lord Cohen of Birkenhead for permission to publish Case 2 and to Professor C. A. Wells (on behalf of the late 
Mr. M. Silverstone) for permission to publish Case 3. Professor T. N. A. Jeffcoate saw both these cases and refers briefly to Case 3 in his Principles of Gynaecology.

\section{REFERENCES}

Adam, G. S. (1947). J. Obstet. Gynaec. Brit. Emp., 54, 358

A (1954). Demonstrations of Physical Signs in Clinical Surgery.

12 th ed. Wright, Bristol.
Beebe, R. T., Powers, S. R., and Ginouves, E. (1958). Ann. intern. Med., 48, 834.

Begg, R. C. (1927). Surg. Gynec. Obstet., 45, 165.

C.

Cox, H. T. (1945). Brit. J. Surg., 33, 182

Culbertson, C (1925). J. Amer. med. Ass, 85, 1955.

Cullen, T. S. (1916). Embryology, Anatomy, and Diseases of the Umbilicus.

Saunders, Philadelphia.
(1918). Amer. J. Obstet. Dis. Wom., 78, 457.

and Brödel, M. (1937). Bull. Johns Hopk. Hosp., 61, 295

Fallis, L. S. (1937). Ann. Surg., 106, 54.

Fallon, J., and Manning, J. J. (1949). New Engl. J. Med., 240, 747.

Galloway, W. D. (1939). Trans. New Engl. obstet. gynec. Soc., 1937, p. 56

Gerrard, E. A. (1938). Clin. J., 67, 162.

Goinard, P., and Curtillet, A. (1934). Bull. méd. (Paris), 48, 38.

Gold, V. (1926). Zbl. Gynäk., 50, 2206.

Gough, W. (1939), Trans. New Engl. obstet. gynec. Soc., 1937, p. 56

Greig, G. W. V., and Shucksmith, H. S. (1950). Lancet, 1, 4.

Hadley, H. G. (1940). Northw. Med. (Seattle), 39, 91

Halperin, G. (1928). Surg. Gynec. Obstet., 47, 861.

Higgins, G. M., and Graham, A. S. (1929). Arch. Surg. (Chicago), 19

Jackson. F. H. (1922). J. Amer. med. Ass., 79, 1929.

effcoate, T. N. A. (1957). Principles of Gynaecology. London.

Med. 35, 144

Johnston, L. B. (1930). J. Amer. med. Ass., 95, 1587.

. R. (1925). 16id., 84, 1107.

Neumann, A. G. (1928). Bol. Soc. Obstet. Ginec. B. Aires, 7, 386

Neumann, A. G. (1928). Bol. Soc. Obstet. Ginec.

Paucot, H. (1924). Bull. Soc. Obstét. Gynéc. Paris, 13, 631

Perman, E. (1922). Acta chir. scand., 54, 434.

Perman, E. (1922). Acta chir. Scand., 54, 434.

Pfeiffer (1923). Referred to by L. Fraenkel, Zbl. Gynäk., 1924, 48, 543.

Poirier. P., and Charpy, A. (1912). Referred to by Cox (1945).

Ransohoff, J. (1906). J. Amer. med. Ass., 46, 395.

Rivas, M. R. (1950). Amer. J. Roentgenol., 64, 723.

Roberts, H. (1949). J. Obstet. Gynaec. Brit. Emp., 56, 976.

Sacbs, L., and Macht, A. H. (1953). Bull. Sch. Med. Maryland, 38, 99.

Schmitz, E. (1932). Med. Klin., 28, 756.

Schumann, E. A. (1923). Amer. J. Obstet. Gynec., 6, 632.

- (1936). A Textbook of Obstetrics. Saunders. Philadelphia.

Smith, I., and Wright, F. J. (1935). Lancet, 1, 930.

Stablei, F. (1934). Brit. med. J., 2, 255.

Sternberg, H. M. (1922). J. Amer. med. Ass., 79, 1841.

Stoeckel, W. (1901). Zbl. Gynäk., 25, 241.

Strube, H. (1923). Z. Geburtsh. Gynäk., 86, 382.

Stutzer, E. (1931), Zbl. Chir., 58, 597

Teske, J. M. (1946). Amer. J. Surg., 71, 689.

. Amer. J. Surg., 71 ,

Torpin R (1943) Amer. J Obstet. Gynec. 46, 557

Torpin, R. (1943). Amer. J. Obstet. Gynec.

Turner, G. G. (1920). Brit. J. Surg., 7, 394.

Wakeley. Sir C. (1952). Brittsh Encyclopaedia of Medical Practice, 2nd ed. 9, 384 . Butterworth, London.

Way, S. (1941). J. Obstet. Gynaec. Brit. Emp., 48, 473.

Wilens, I. (1936). Amer. J. Surg., 33, 296.

Zohman, B. L. (1933). Med. J. Rec., 137, 232

The institution of Fire Engineers has had prepared three coloured filmstrips, with lecturer's notes, on fire precaution in hospitals. The first deals with the causes of fire, the second with fire-fighting and means of escape, and the third with the evacuation of patients. The filmstrips and notes were made by the department of medical illustration of the South Manchester Hospital Group and the Manchester Royal Infirmary in collaboration with the Manchester Fire Brigade, and are intended primarily for nursing staff. Whilst fire brigades can arrange periodic inspections of hospital premises, technical experts on fire prevention are not always free to fit in with hospital training courses. It is hoped therefore that the filmstrips and notes will provide useful material for the lay lecturer. Each filmstrip (with its notes) costs two guineas, and copies are obtainable from Chantry Publications Ltd., 63, Neal Street, London, W.C.2. In 1956, according to figures from the Joint Fire Research Organization, there were 452 fires in hospitals in England and Wales, 32 in Scottish hospitals, and 8 in hospitals in Northern Ireland. The commoner causes, from a 5-year analysis of fires in hospitals and homes and institutions for the care of the sick and infirm, were smoking (18.3\%), electric apparatus, heaters, and fires $(14.3 \%)$, fires in grates $(11.5 \%)$, gas apparatus $(9.3 \%)$, electric wiring $(6.3 \%)$, and slow combustion stoves $(5.9 \%)$.

\section{ACUTE RESPIRATORY DISEASE IN THE R.A.F., 1955-7}

BY

J. C. McDONALD, M.D., S.M., D.P.H.

Epidemiological Research Laboratory, Colindale, London

\author{
J. S. WILSON, M.B., D.P.H.
}

Air Commodore, Royal Air Force

W. B. THORBURN, M.B., D.P.H., D.I.H.

Wing Commander, Royal Air Force

W. W. HOLLAND, B.Sc, M.B.

Flight Lieutenant, Royal Air Force

AND

B. E. ANDREWS, M.R.C.S., Dip.Bact.
Virus Reference Laboratory, Colindale, London*

In a survey of acute respiratory disease in the Royal Air Force in the winter of 1954-5 (Andrews et al., 1956) about half the admissions to sick-quarters with a respiratory illness were due to influenza $\mathrm{B}$, which was prevalent in the United Kingdom at that time. Identifiable virus infections caused only a small proportion of the remainder, but an outbreak due to adenovirus infection was found in one of the ten stations observed (R.A.F., Stafford) and had been responsible for a few cases in another station (R.A.F., Kirkham) just before the survey began. Three of the six strains of adenovirus isolated from these two stations were examined for type: one was type 4 , one type 14 , and one was untypable by any of the sera then available. Several investigations in American service units have shown that adenovirus infections are most prevalent among recruits (Hilleman et al., 1955 ; Berge et al., 1955 ; Rowe et al., 1956 ; Woolridge et al., 1956 ; Hilleman et al., 1957). Further surveys were therefore made during the winters of 1955-6 and 1956-7 aimed at defining more clearly the importance of influenza virus and the adenoviruses in causing acute respiratory disease and invaliding from the Service.

\section{Materials and Methods}

1955-6.-At 25 stations in England and Wales a standard record card was completed by the unit medical officer for every patient admitted to station sick-quarters for over 48 hours between October, 1955, and April, 1956. Four of the stations were for apprentices or boy entrants aged from 15 to 18 years; the remainder were operational units. In all cases of acute respiratory disease an attempt was made to obtain 5 to $10 \mathrm{ml}$. of blood on admission, and a further specimen 14 to 21 days later. Paired sera were obtained from 1,394 patients $-70 \%$ of all those admitted with an acute respiratory illness at these stations. The proportion of illnesses tested from boys' units was $58 \%$ and from operational units $79 \%$. In addition, at four recruit stations record cards and paired blood samples were requested from up to 10 recruits admitted each week with an acute respiratory illness. A total of 281 paired sera were thus obtained, representing $8 \%$ of acute respiratory admissions at these stations. Throat swabs for virus isolation were taken from a few recruits whenever there was evidence of an outbreak. The ends of the swabs were broken off into $5-\mathrm{ml}$. bottles containing $2 \mathrm{ml}$. of virus transport medium $(0.5 \%$ lactalbumin hydrolysate in Hanks's solution) and taken to the laboratory on solid carbon dioxide.

*Now at the Public Health Laboratory, Monsall Hospital, Manchester. 